\title{
A theory of psychosomatic medicine: An attempt at an explanatory summary*
}

\author{
WOLF LANGEWITZ
}

\section{Abstract}

This article investigates issues in psychosomatic medicine that could broadly be seen as concerned with the status of 'subjective' and 'objective' realms. Initially, it considers two seemingly opposing perspectives, the biomedical model and the constructivist/semiotic model. The bio-medical model has all the set-backs of a positivistic and deterministic model: there is an unambiguous reality that can be ascertained given a detailed enough analysis. It furthermore assumes that observations can be explained by the application of linear causal relationships between the single components of reality. The constructivist perspective and the semiotic way of thinking view life and individuals moving through their life as dealing with particular signs; by applying semiotic thinking we understand why certain elements were selected out of the environment and why they were given a specific meaning. It suggests that some of the difficulties arising from these models can be ameliorated with reference to the neo-phenomenology of Hermann Schmitz. In particular, the concept of the lived body (Leib) assists in understanding the relationship between a patient and his environment.

Keywords: medicine; psychosomatic; behavior; psychotherapy; psychoanalysis; von Uexküll.

In 1998 Uexküll and Wesiack presented the third edition of their textbook Theory of Human Medicine - in its 550 pages it attempts to portray the basic thinking and clinical practice of physicians (von Uexküll and Wesiack 1998). The authors, particularly the recently deceased Thure von Uexküll, have tried to encourage their colleagues to think about the model that forms the basis of their medical thinking and practice. If medicine could be described as the interaction of human beings with human 
beings then the main purpose of this model is the human conception of medicine.

If one follows the critical thinking of Thure von Uexküll, the main problem with medicine is that it either propagates a medicine for bodies without minds or a medicine for minds without bodies. In the introduction of the first edition of his standard work Textbook of Psychosomatic Medicine he wrote: 'Somatic researchers quote Naunyn: "Medicine will be science - or it will not be." Psychosomatic researchers refer to Viktor von Weizsäcker: "Psychosomatic medicine will be psychoanalysis - or it will not be." Medicine will ... have to find a synthesis for both' ( $\mathrm{T}$. von Uexküll 1979).

\section{A theory of psychosomatic medicine versus a theory of medicine}

What should a theory of psychosomatic medicine achieve? Two approaches can be described through which an answer appears possible a salutogenetic and a pathogenetic approach.

From a salutogenetic perspective, according to Antonovsky, one could argue that theories contribute to our lives by implanting a network of meaningful concepts into the world we live in. They make the world understandable and introduce a sense of coherence in the person who applies the theory. Antonovsky describes this as:

... a global orientation that expresses the extent to which one has a pervasive, enduring though dynamic feeling of confidence that one's internal and external environments are predictable and that there is a high probability that things will work out as well as can reasonably be expected. (Sack and Lamprecht 1998)

This feeling of coherence is made up of three components, from which at least the first two can be supported by the knowledge and application of a theory: comprehensibility (life events are predictable or at least classifiable in a context) and manageability (the trust that demands can be met with one's own power), and meaningfulness (life events are viewed as demands that are worth the effort to solve them).

From a pathogenetic perspective one could ask: Which evil befalls physicians or clinical researchers when they delve into 'psychosomatic problems' or even into the realm of explanatory models in Psychosomatic Medicine? The most likely cause is the experience of being unable to act or to understand what is happening between the professional and the patient. Two examples can illustrate this: 
- A colleague from plastic surgery referred a 34-year-old man who desperately wanted a third operation on an inguinal hernia because he was experiencing severe, mostly burning, pain in the area of the $\mathrm{N}$. cut. fem. lat. The patient engaged in endurance training, in swimming, biking, and walking about five times a week for about 2-3 hours per training session. The reason for the referral was the surgeon's fear that the situation could not be improved by yet another surgical procedure (neurolysis).

- A general practitioner referred a 43-year-old patient whose inability to work had not improved, even after two years of conversational therapy (most likely in the sense of a patient-centred psychotherapy). The patient reported periods of stiffness and pain in his trunk and leg muscles lasting for hours, impaired vision, some dizziness, as well as burning and tightness of the chest. During psychotherapy the doctor had understood very well why the pain arose for the first time two years ago; unfortunately this alleviated the patient's problems only temporarily. The patient's wife was now pregnant again and he was worried about the family income. During the conversation a tense atmosphere arose, the therapist became uneasy and reacted very irritatedly and angrily to a knock on the door, although he had asked the craftsman to report to him by all means before leaving.

In both instances colleagues were searching for help because their explanatory models were neither sufficient for understanding the patient's behavior nor helpful to present instructions on how to proceed. In both instances an interest in psychosomatic thinking and action arose from the experience of a deficiency in the implicitly available or consciously applied models of either psychotherapy or somatic medicine.

In the development of a theory of medicine several problems should be addressed. They were already persuasively formulated by Uexküll and Wesiack in the first edition of the later so-called 'Uexküll - Textbook of Psychosomatic Medicine' (T. von Uexküll 1979). In the first chapter the problems are formulated as follows:

1. We have seen that we may not regard the individual and the environment separately. So we are presented with the problem of how their inter-relation can be described in a concise concept in order to present doctors with detailed instructions for their diagnostic and therapeutic tasks.

2. Even if one successfully develops a language for the layer of social interactions, the layer of physiological changes, and the layer of subjective perception, the second problem lies in the creation of a model that is capable of interpreting the connections between these three domains. ( $T$. von Uexküll 1979: 9) 
I might add:

3. Even if one manages to comprehend biological, psychological, and social findings and to describe them in their respective languages, even if a method for the analysis of their mutual relationship has been created, there is still no answer to the pertinent question: Why did this person fall ill at this moment?

A theory of psychosomatic medicine should not only provide explanations regarding the experience of a patient and the process between doctor and patient, but it should also be capable of alleviating the typical dilemma of psychosomatic physicians who report jumping back and forth between the somatic and the psychosomatic world in their everyday clinical practice. Many of these doctors avoid this problem by giving up their somatic discipline and treating patients as psychotherapists only. Hence, a further question emerges:

4. How can the change from a somatic identity, which is mainly rooted in the bio-medical model, to a psychotherapeutic identity be described and made useful?

\section{A summary of the scientific theory of medicine}

Most widely used is the scientific model of medicine that has been derived primarily from physics. Nature sciences generate general statements, which are put to the test through experiments. In order to obtain clear, unequivocal results, the degrees of freedom of test animals and patients must be restricted as much as possible. Data generated under 'standardized conditions' allow for the construction of linear cause-effect relationships. From this perspective, humans behave like a trivial machine in which every input (e.g., in the form of a pharmaceutical agent or an operative intervention) can be adequately assigned a carefully planned and predictable output (e.g., lowering blood pressure or stabilization of joints). Undoubtedly, this model has enabled enormous success, especially in emergency medicine or in diseases with a rapid onset and of short duration. It is also clear, however, that chronic diseases and disorders which arise from the behavior of individuals cannot successfully be explained or addressed through a purely scientific model. Wade and Halligan (2004) described three assumptions that account for the limited use of a purely bio-medical model: all illness has a single underlying cause, disease (pathology) is always the consequence of the single cause, and removal or attenuation of the disease will result in a return to health. They add the following as components of a reductionist model: 
- All diseases give rise to symptoms, eventually if not initially, and although other factors may influence the consequences of disease, they are not related to its development or manifestations

- Health is the absence of disease

- Mental phenomena, such as emotional disturbance or delusion, are separate from and unrelated to other disturbance of bodily function

- The patient is a victim of circumstance with little or no responsibility for the presence or cause of the illness

- The patient is a passive recipient of treatment, although cooperation with treatment is expected.

\section{Jakob von Uexküll's model of the functional cycle: The roots of semiotic theory and constructivism}

In order to answer the first question, (How can the interplay of environment and individual be described in a concise concept?), Uexküll and Wesiack referred to the environmental theory of Jakob von Uexküll. The latter described the 'functional cycle' that governs the interaction between an organism and its environment.

From the multitude of different factors surrounding it, the organism chooses elements that are relevant in the actual situation. In doing so, it converts surrounding into environment, to which only those elements belong that are relevant at the present moment. The organism is thus embedded in a 'dwelling-integument' that contains everything that is important. With this perspective, J. von Uexküll contradicted the dogma of a positivist world view that assumes one single reality, uniform for different organisms (J. von Uexküll 1980). In the functional cycle a basic assumption of constructivism is presumed: organisms construct their subjective world by selecting some elements and by assigning a certain meaning to these elements depending on their inner state. In the tradition of this thinking, organisms create meaning - elements in the world 'out there' do not have an inherent meaning themselves.

The work of the Chilean biologist and cognitive scientist Humberto Maturana has been very influential in the development of constructivist approaches in psychosomatics (Maturana and Varela 1987). He created the term 'autopoietic organization' as an important differentiation between the living and the non-living (Maturana and Varela 1987). An autopoietic organization is an autonomous and self-maintaining unity that contains component-producing processes. They perceive outer stimuli as perturbation (disturbances) to their constantly ongoing inner process, to which they react, depending on their momentary needs. Energy from the 
outside can shape the living system, but it cannot determine it. Even the perception of senses such as sight and hearing are not an image of a unique and definite reality around us, but individual constructions (Langewitz, Degen, and Schächinger 2003: 754). This model has large-scale consequences for medicine and psychosomatics, which mainly incorporates the following points:

A therapist cannot determine how his/her patient is seeing the world and him/herself in this world only by observing him or her. A (partial) common reality must be constructed between a professional and a patient. From this, the basics of communicative medicine can be derived because doctor and patient must constantly agree on the momentarily valid elements of reality and on their significance. One exception should be considered: in emergency medicine the elements of the common reality of the doctor and the patient are usually immediately evident between the two without further explication. Otherwise, the diversity of potential reactions of an organism to different outer influences is unpredictable because the individual's inner state cannot be predicted with sufficient precision.

The functional cycle contains core elements of a semiotic theoretical approach: If not all elements in the environment of an individual are automatically part of his subjective world, they become so only after a basic meaning has been attached to them: this and that is important at the moment (e.g., in a state of hunger), because it serves actual needs; moments later this predicate is attached to other objects or situations. In a state of hunger, fruit will be given the predicate of relevant and become part of the subjective environment; eating it relieves hunger, and with satiety being achieved, a fruit loses its privilege of being relevant. This example illustrates that we must be dealing with a two-step sign process: in the first step something is chosen as RELEVANT out of the diversity of the cues surrounding us; in a second step this so called perception sign is assigned a specific meaning; it initiates a behavior through which the organism sends out an effector sign into its environment (see figure 1). In simple cases such as the case of the fruit in the presence of a hungry animal, the perception sign disappears after the impact of the effector sign (at least from the externally visible environment): the effector sign erased the perception sign.

Although he does not describe his model of biology as semiotic, Jakob von Uexküll is known by his successors as the founder of the biosemiotic perspective (Hoffmeyer 2003). The clinical significance of the functional cycle model can be illustrated well by the above mentioned example of the sporty man: 


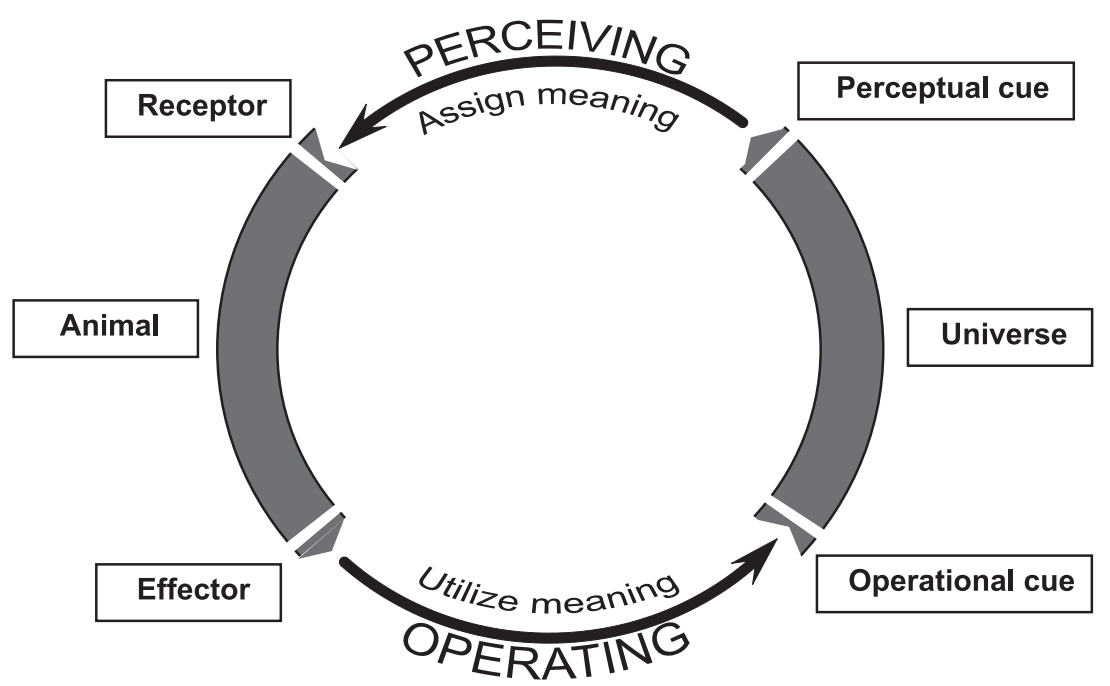

Figure 1. Functional cycle according to Jakob v. Uexküll

During their first meeting the therapist notices that the patient touches or even intensely massages the painful area on the side of his thigh several times a minute. Most of the time, this gesture is accompanied by a facial expression of pain. From a constructivist perspective we observe a process of selection. Out of the manifold proprioceptive impressions, the problem area is addressed; it is therefore very likely to become a dominant part of the subjective reality of the patient. When the therapist informed the patient about his observation he was surprised because he had not intentionally touched this spot in his upper thigh. Therapist and patient agreed upon the following description of their observations: 'Without a conscious prompt, "the body" constantly produces new impressions that yield confirmatory evidence that something isn't right in that part of the body.' The consequence of this automatic behavior is that the problem area is never forgotten; it is forced into the foreground of reality. When this process, in the sense of a self-perpetuating cycle, prevents the intensity of the pain being reduced, it may be helpful to consciously control and reduce the frequency of contact. Subsequently the patient agreed that the therapist signals whenever he is touching the problem area in the remaining minutes of the session. He is surprised how seldom he notices that 'the fingers of the right hand became active.' He decided to explain the situation to his partner and to have her help him to become aware of his behavior more precisely. In the next session, he 
reports that the intensity of the pain/discomfort has been reduced by about 80 percent.

\section{How does the interaction of biological, physical, and social factors function?}

The semiotic perspective in the discussion of the above drafted questions in psychosomatic medicine seems attractive: under specific premises it offers an answer to the second question: physical, social, and biological processes and their interactions can be completely described in the terminology of semiotics. This had been formulated in 1979 when T. von Uexküll and Wesiack saw the potential of semiotic thinking for a theory of medicine:

Semiotics can gain a special importance in medicine - especially for psychosomatic medicine - by helping us to overcome the dichotomy of soma and psyche. The basic difference between (subjective) complaints and (objective) findings becomes irrelevant by the application of a theory of information. (T. von Uexküll 1979: 78)

The works of Charles Sanders Peirce (1839-1914), who is described by many as the father of modern semiotics, are considered important resources for the semiotic position and have been consulted by Thure von Uexküll's group. With reference to C. S. Peirce we must however keep in mind that he addressed psychosomatic questions understood in today's terms only indirectly. We should therefore quote Peirce with the precaution in mind, whether we indeed do him justice at all in quoting him in relation to our psychosomatic models.

\section{Semiotic thinking and C. S. Peirce}

Jakob von Uexküll formulated the inseparable connection of organisms and their environment in the functional cycle. A central element therein is the process of assigning meaning: After taking notice of it, an organism interprets an element (sign) of its environment in a very specific manner and then displays behavior according to the meaning which the sign was given. One can describe this process very precisely in terms of C. S. Peirce's sign theory. Peirce added the interpretant in between the object and the sign. According to a late phrasing from the year 1907: 
I will say that as a sign is anything, of whatsoever mode of being, which mediates between an object and an interpretant; since it is both determined by the object relatively to the interpretant, and determines the interpretant in reference to the object, in such wise as to cause the interpretant to be determined by the object through the mediation of this 'sign' ... The object and the interpretant are thus merely the two correlates of the sign; the one being antecedent the other consequent of the sign. (EP 2: 410)

This way of thinking makes Peirce attractive, first of all, for the explanation of diversity in patients' behavior that often strikes clinicians treating patients with seemingly similar states of disease; in spite of a similar 'objective load' and impairment, patients adapt to their illness in unpredictable and diverse ways. In Peirce's terms, we might say that different ways of adjusting arise from the formation of different interpretants that refer to different objects or situations.

However, this straightforward application of Peirce's taxonomy looses its attractiveness or applicability to clinical situations if one tries to apply precisely his complex list of signs, interpretants, objects, and relations between them. In that case, one soon feels like the editor of Peirce's collected works, who wrote in the introduction:

as anyone knows who has tried to work out examples of Peirce's classes, it is not as easy as we might think - which means either that we do not quite understand Peirce or that this theory is a bit ambiguous. (Houser and Kloesel 1992: xxxvii)

Problematic for Peirce's role as a source for the semiotic perspective in psychosomatics is however, that many of his writings allow the assumption that he restricted interpretants to those signs that develop distinctly in the mind of the interpreter. If we assume that people's behavior is governed by unconscious thoughts at least as much as by logical reasoning, this position is difficult to accept. A further reason for scepticism from the psychosomatic perspective is Peirce's clear position regarding the decisive role of the five senses that is best depicted in his famous dictum:

The elements of every concept enter into logical thought at the gate of perception and make their exit at the gate of purposive action; and whatever cannot show its passports at both those two gates is to be arrested as unauthorized by reason. (EP 2: 241)

This reduces the human capability of perception to material that has unequivocally travelled along neuronal axes from sensory organs to the brain. It denies human beings the ability to realize synesthetic characters like paralyzing or solemn silence. How could a mere lack of acoustic 
phenomena (silence) bear these meanings? The above quotation from Peirce does not offer a solution! However, there are other statements by Peirce in the very same essay that soften the rigorous sensualistic reduction, according to Schmitz (1995: 21):

But the sum of it all is that our logically controlled thoughts compose a small part of the mind, the mere blossom of a vast complexus which we may call the instinctive mind in which this man will not say that he has faith because that implies the conceivability of distrust, but upon which he builds as the very fact to which it is the whole business of his logic to be true. (EP 2: 241)

In another part he emphasizes that a sign does not primarily cause a logical interpretant (as a thought) in the consciously thinking 'mind,' but that it initially causes feelings. They present a first impression of the meaning of a sign (the emotional interpretant). Furthermore, a sign should cause an impulse (effort); he calls these interpretants the energetic interpretants (EP 2: 409).

\section{Peirce's triadic semiotics and its clinical application}

The term triadic semiotics describes the trinity of semiotics, which is categorized into object-sign-interpretant and distinguishes Peirce's semiotics from the semiotics of de Saussure, which differentiates between 'signifiant' and 'signifié,' and is based on a two-sided sign process. 'Le signifiant' describes the form that a sign assumes and 'le signifie' the concept that it represents. The relationship between the two is explained as signification (Saussure 1983 [1916]: 67). A further case study might help to demonstrate why a triadic semiotic perspective, according to Peirce, can be useful for a therapeutic process:

A patient reports recurrent phases of acute shortness of breath, for which no biological reason has been found. The problem started during a ENT-examination, during which she suddenly resisted the ENT-doctor who held her tongue and had pulled it out in order to inspect her vocal chords. Because no one could tell where the shortness of breath came from, she ended up in a psychosomatic outpatient department. $E C G, X$-rays of the lungs, lung function tests, etc. had yielded normal results.

In an attempt to translate this situation into a triadic sign system, it is evident that the definition of a starting process of a semiosis is an arbitrary decision. We are confronted with chains of signs, interpretants, and objects. In this case report we might choose to start with the fact that she 
opened her mouth wide in the presence of a doctor (male?). Translating this into a semiosis we might say:

'It seems that the fact that Dr. X asked you to open your mouth put you in a state of agitation with very unpleasant feelings. It caused the immediate wish to get out of the situation.'

Or: opening the mouth acts as a sign, which elicits an obviously negative emotional interpretant and a strong energetic interpretant; both refer to an unknown situation/an unknown object. In Peirce's notation one could write:

\title{
Object/Situation: UNKNOWN
}

Sign: 'Open your mouth!'

\author{
-Energetic interpretant: Go away! \\ -Emotional interpretant: Fear!
}

The patient thinks about this proposal and then adds: 'I think it has something to do with the fact that he was sitting so close to me, his knees in between mine.'

'So it is a combination of opening your mouth and the physical proximity to a man that triggers this uncomfortable situation? Even if you cannot recall what is loading this encounter with so much meaning we are left with some knowledge: there must have been a situation in which such a combination of signs elicited similar interpretants. What we also know is that this situation somehow developed into shortness of breath.'

The patient takes up the term 'shortness of breath' and during the next three meetings the therapy centres around recognition and avoidance of hyperventilation. Practicing breathing exercises (breath holding, relaxed breathing, panting, humming) she remembers that her two older brothers used to play a game with her: all three threw their blankets on their parents' large bed, they all jumped on top and somehow rolled around under and between the different layers. If they got hold of someone else they tried to tickle the other who tried to escape into another layer of blankets. Sometimes she ended up in the bottom layer and was afraid she might suffocate. She then fought like mad to free herself.

Here, an individual history can be reconstructed for at least one interpretant: There was a situation in which the desperate urge to 'break free' (energetic interpretant) arose from the perception of not being able to breathe (sign), which was (probably) related to an increased $\mathrm{pCO}_{2}$ level (object/situation).

Afterwards the patient reported that she tends to overuse anti-congestants when she has caught a cold; for years she has always tried to avoid the sensation of restricted breathing through her nose. 
In the fourth meeting she mentioned a trip to the dentist with her son in the preceding week. She suddenly had realized that there had been something during her childhood that she would like to talk about now. In tears and with heavy breathing she is relating to a series of treatments at the age of 6 or 7 . She remembers the dentist pressing up against her arm on the armrest of the dentist chair; she does not recall whether anything 'real happened.' She just re-experienced the sense of helplessness and disorientation, not knowing what exactly was going on, sensing however that something was not as it should be.

The origin of a further interpretant became clear with this story: The fear of a young girl (emotional interpretant) was triggered by the combination of her mouth being locked open and the physical closeness of a man (sign), which refers to the abuse of a professional relationship in her life history (situation/object).

One might ask whether thinking in Peircean categories allows for such reasoning. I think this attempt to rebuild the past situation surrounding actual interpretants is justified; in a letter to William James from the year 1909, Peirce clarified that a sign determines a potential Mind only when this mind possesses additional information concerning the object. He wrote:

A person who says Napoleon was a lethargic creature has evidently his mind determined by Napoleon. For otherwise he could not attend to him at all. But here is a paradoxical circumstance. The person who interprets that sentence (or any other Sign whatsoever) must be determined by the Object of it through collateral observation quite independently of the action of the Sign. Otherwise he will not be determined to [the] thought of that object. If he never heard of Napoleon before, the sentence will mean no more to him than some person or thing to which the name 'Napoleon' has been attached was a lethargic creature. (EP 2: 493)

The same holds for the interpretant; he also has a history in which collateral observations were collected (EP 2: 494-495).

\section{Peirce's semiotic and its use as an integrative perspective for different psychotherapeutic trends}

In my opinion, a semiotic perspective could contribute to the explanation of basic similarities in different psychotherapeutic models: if we assume that prior experiences affect our interpretation of the momentary environment - not only in the assessment of what we perceive, but also in the choice of what we perceive - then the material being dealt with, for example, in psychoanalysis and behavior therapy, shares one element 
in common: an attempt to reconstruct the development of interpretants. The main difference would then be due to different timelines that are applied in the attempt to understand current interpretants and signs. The typical behavioral therapist would ask: 'When precisely was the last time you experienced this problem? Could you accurately explain the situation to me?,' while the psychodynamic therapist, after the description of the patient's problem, will be more interested in whether or not something similar happened in the past going back to the patients' childhood. Additionally, according to Peirce, one could easily assume that the isolation of interpretants on a purely cognitive level does not make much sense effort and feeling are almost always present before the actual thoughts. The more cognitive behavioral therapy acknowledges that even nonconscious signs can trigger interpretants, the more the dispute between the representatives of different therapeutic schools could focus on the effective ingredients of psychotherapy - for example, on the question of how important trust in the good intentions of the therapist is, etc.

For psychosomatic thinking and psychosomatic therapy in general, one might think about the question to what extent therapeutic intervention should be seen as 'working on interpretants.' This is explicitly the goal of cognitive behavior therapy when their supporters talk about dysfunctional concepts, reframing concepts, etc. All these terms can be directly translated into 'working on the interpretant.'

\section{Peirce's world of the unknown}

What must happen for humans to decide to seek medical help? If we disregard acute injuries or other emergency situations like a sudden collapse or inability to breathe, humans perceive something that just tells them: "something is "not good"! If someone presents this vague sensation of 'not good' to a physician, s/he will be confronted with a list of closed questions that ask for a meticulous description of the problem. According to Peirce this vague and miscellaneous state belongs to the category of Firstness. He calls signs within firstness iconic signs. His description of Firstness is as follows:

The First is that whose being is simply in itself, not referring to anything nor lying behind anything ... The First must therefore be present and immediate so as not to be second to a representation. It must be initiative, original, spontaneous, and free; ... it cannot be articulately thought: assert it, and it has already lost its characteristic innocence; for assertion always implies a denial of something else. Stop to think of it, and it has flown!... Only remember that every description of it must be false to it. (EP 1: 248) 
The fact that Peirce's signs of Firstness are ultimately inaccessible for a discourse makes them difficult for an inclusion in a theory of psychosomatic medicine. We know of their existence, but do not perceive them clearly; we might become aware of them in the no man's land just before being fully awake. Peirce gives a vivid example of these phenomena in the story of a man, whose bed clothes catch fire (EP 1: 283). We forget signs of firstness as soon as we are able to separate them out from the surrounding signs as being unique.

Freud has pointed to the paramount importance of vague perceptions. He recommends that the psychoanalytical therapist dedicates himself to the indefinite and to consider everything that he comes in contact with the same serious interest. In his 'Recommendations to physicians practising psychoanalysis,' he wrote:

However, this technique is a very simple one. It rejects all kinds of technical aids ... even taking notes. It simply consists of an attitude of abstaining from remembering specific elements of what is said. Foremost is the willingness to meet what so ever is brought up with evenly sustained but free-floating attention. On the other hand, as soon as one deliberately strains attention to a significant extent, one starts to actively select from among the material being presented. (Freud 1912: 376)

\section{Hermann Schmitz' neo-phenomenology}

I would like to briefly present Hermann Schmitz's neo-phenomenology as a third theoretical reference. From my understanding, his theory stems from the deficits of the two other models: the bio-medical model has all the set-backs of a positivistic and deterministic model: there is an unambiguous reality that can be ascertained given a detailed enough analysis. It furthermore assumes that observations can be explained by the application of linear causal relationships between the single components of reality. The constructivist perspective and the semiotic way of thinking view life and individuals moving through their life as dealing with particular signs; by applying semiotic thinking we understand why certain elements were selected out of the environment and why they were given a specific meaning.

The examples above however, might also have shown that this type of post hoc semiotic interpretation of an interaction between patient and therapist is far away from the actual experience of patient and therapist. This however - experiences that 'on the average everybody can vividly access or retrieve from his memory' is the basis for the philosophical rea- 
soning of Hermann Schmitz's (b. 1928), who laid down his system of philosophy in a ten volume oeuvre. Schmitz clearly rejects the semiotic position, in which primarily polyvalent or non-meaningful signs receive their meaning in the mind of an observer. He contradicts the assumption that 'subjects who are positioned opposite to the world are projecting meaning into a world that primarily is indifferent' (Schmitz 1997: 186). Particular items can only be distinguished if they belong to a certain category. Meaning is therefore primarily present and not the result of an attribution by the interpreter of a situation (Schmitz Marx, and Moldzio 2002: 63). Except for a state of trance or ecstasy 'Everything that is distinctly experienced, and everything that is single in the sense that the number of a category increases by one, is (already) charged with meaning' (Schmitz 2003: 89). It would, however, be impossible for humans to move through a world of myriad particular items that are already loaded with meaning. This was no problem for Jakob von Uexküll because he believed that the organism does not move through a barrage of meaningful signs, but through a world mainly consisting of dimensionless and meaningless particles from which certain ones are chosen and become part of the subjective environment. In the functional cycle and according to Peirce, it is however not clear how a sign moves into the foreground of perception so that it is being noticed and initiates a semiosis. Doesn't this call for a certain meaning sui generis? At least a meaning like: 'Take notice of me? Pay attention!' Posed like this the question of how signs - including inner bodily perceptions - manage to get a box seat in the patient's mind is of great importance in psychosomatic medicine: how does, for example, an almost subliminal perception of vertigo become so important that it keeps the perceiving individual with a somatoform disorder from leaving home? Eco discovered a similar 'pointing' characteristic of signs in Peirce's term 'ground,' which they possess before referring to the process of semiosis of the actual object (Eco 2000: 126).

Schmitz' thinking takes another direction: If the world would indeed consist of myriad elements that all have a circumscribed meaning, we would loose orientation in a whirlwind of details. This does not happen, however, because we normally live embedded in situations and not in constellations. Situations are characterized by a unified entity (Gestalt) that stands out from the environment, meaningfulness consisting of facts, programmes, and problems; situations have 'something to say'; diffusion within the situation: not everything contained can be listed as single items; meaningfulness is dissolved in chaotic manifoldness (Schmitz 1999: 21). Our own language is a typical situation: we move through our mother tongue without paying attention to precise rules or to the etymological derivation of a term that we are using. Learning a foreign language takes 
place inside of a constellation. Constellations are (complex) arrangements of particular items that can finally be understood.

The following few terms, which have been taken out of Schmitz's work, could in my opinion be helpful for the development of theories in psychosomatic medicine. Again, as with Peirce: it is risky to excise single components out of a complex work and transfer them into another theory. Using Schmitz' terms we may hope that the basic character of the meaning is maintained, while certainly some of the precision of the term intended by the author is lost; Schmitz decidedly commented on medical and psychotherapeutic problems, he set out a comprehensive theory of the felt body and wrote about human communication (see Langewitz 2007 and Schmitz 2004a).

Hermann Schmitz critically distances himself from the philosophical tradition of the Western world, which has had a major impact upon research paradigms in natural sciences, as well. He traces back the roots of Western philosophy to Democritus,

who was the first to propose a division of the human being into body and mind; mind being viewed as a closed, private inner world, similar to a house, with the senses as the only witnesses of the world outside. This leaves behind a reduced outer world, in which according to Aristotle there are only three types of characteristics (Substance, Matter, Form) which have atoms as their carriers. (Schmitz 2004a: 148)

Different things arise from the (re-) arrangement of atoms much like tragedies and comedies contain the same characters. This view is the emblem of constellationism: The world (at least the outer world) is seen as a constellation of (enmeshed) single items just like a text is a constellation of letters. (Schmitz 2004a: 148)

With this principle in mind it is only logical that natural sciences continue looking for smaller entities within the bio-medical model; applications of nano-technology or the Human Genome Project could be viewed as being driven by the assumption that, in the end, life and most diseases could be described as the (false) arrangement of observable units in a deterministic model.

\section{Feelings as atmospheres poured out rimless}

We all have had the experience of a room filled with a certain atmosphere; we realize immediately if 'trouble is brewing' even if we do not know the individuals sitting together nor what they have been talking about (Schmitz 1995: 292). This familiar observation is used by Schmitz 
to argue against the exclusively private nature of feelings; they are by no means locked in 'the soul' of a person, accessible only through the intimacy of a dyad or of a therapeutic group. It does not take specific utterances (crying, screaming, quirking eyebrows); even a room with no human being in it can breathe a certain atmosphere. How do feelings as atmospheres exert their power over human beings? Schmitz explains this phenomenon by stating that feelings cause a reaction of the felt body (German: Leib), sometimes taking possession of the affected person completely (Schmitz 1995: 302).

\section{Communication as the interaction of lived bodies (leibliche Kommunikation)}

With this term, Schmitz describes the characteristics of any type of interaction that 'overcomes the loneliness of an individual.' Contrary to the semiotic position set out above, the individual and the environment cannot be thought of as being separate, in opposition to one another, nor could they be imagined as communicating via the exchange of information, for example via impulses travelling along the optical or the acoustic nerves. Schmitz uses the term felt body (Leib) to make a distinction from the body (Körper) the extension of which can be identified through the senses like touch or optical representation. The felt body refers to the sensations one has in the region of the body (Körper) without the use of eyes or hands. The diffuse sensation of 'not doing well,' reported by a patient above is a phenomenon of the felt body that upon presentation to a physician immediately gets transformed into a bodily (körperlich) phenomenon within the realm of single distinctive findings. The interaction of lived bodies occurs even without explicit agreement: it explains why people can pass one another, without much conflict, on a shopping mall just before Thanksgiving, loaded with shopping bags. Bodily communication also includes the interaction with inanimate objects: the smart avoidance of a mass that is rushing towards us threatening physical integrity like a car being on the wrong side of the road is another example of 'bodily communication.'

\section{Switching between a somatic and a psychosomatic identity}

Physicians who engage in psychosomatic medicine, at least in German speaking countries, are not necessarily psychiatrists, but rather qualified primarily in a somatic specialization like internal medicine or gynecology 
- often with an additional qualification in psychotherapy. In daily practice they constantly have to strike a balance between the realm of the uncertain and of subjective facts, which can at best be articulated on one's own behalf, and the realm of objective facts, which everyone can articulate as long as he is knowledgeable enough and able to express himself sufficiently (Langewitz 2008; Schmitz 2003: 15).

I propose that this transition could best be described by Schmitz' terminology: As soon as concrete action is to be taken, particular items like a pleural effusion or suicidal thoughts (objective facts) must be scooped out of the vaguely dispersed meaning of a situation. The same holds for established programs that might pre-exist in the patient's or the physician's stock of similar situations. Talking within a so defined constellation requires analytical intelligence; it explains prosaically. The rest of the situation is discarded as something that (at the moment) does not matter (Schmitz 2004b: 227). Physicians are well trained to leave a situation with vaguely dispersed meaning and to enter a constellation: most medical teachers at university demonstrate their proficiency by rapidly extracting particular items out of the diffuse description of a patient's suffering. The more brilliant they are the faster they ask the one decisive question like: 'Have you been to the tropics in the last year?,' or the faster they perform the one single physical examination like the palpation of the spleen. They demonstrate that there is always a short-cut to the correct diagnosis and thus prove the utility not only of working within constellations but also of the reductionist biomedical model in general. Students normally are not aware of the fact that other doctors - first of all the family doctor have already 'purged' the situation of other meaningful components.

In the many instances in medicine when immediate action is not necessary or when it is not clear how the situation will develop, another type of intelligence is needed. Schmitz describes this kind of intelligence as hermeneutic intelligence, explaining the world poetically:

Like a poet, hermeneutic intelligence is weaving a loose-fitting net of explanations around the phenomenon to be described. The whole, vaguely distributed meaning is not made explicit but so-to-say shining through the meshes of the net. (Schmitz 2004b: 227)

Embedded in a mutual situation, using poetic explication, a physician cannot extract single observations. In that case, instructions for concrete action are difficult to obtain; the conversation remains open for development in all possible directions, until, with the help of a prosaic explication, particular problems are specified for which particular solutions (programs) can be offered. 


\section{What leads to illness — the loss of adaptation (Passung)?}

In the introduction to the first chapter of the first edition of the textbook (1979), Uexküll and Wesiack presented a preliminary answer to this last question: 'We have established that an organism becomes ill, when it enters a situation that it cannot handle.' For psychosomatic theory, the understanding of feelings as atmospheres poured out rimless and the concept of communication as the interaction of two or more lived bodies is promising because these definitions offer an understanding of a central term in the writings of von Uexküll. It is the term Passung probably best translated as adaptation. In the book Theory of Human Medicine, adaptation between organisms and environment is considered a prerequisite for life in general, down to the level of a single cell (von Uexküll and Wesiack 1998: 370). Following these lines of thinking, adaptation occurs when the environment helpfully accommodates the intentions of the organism, providing water to the movement of fins and wind to the feathers of a bird's wings. In that sense, adaptation is central to living: whoever loses the competence of adapting to the environment, falls ill (Adler et al. 2003: 1365). In spite of its centrality in the thinking of Uexküll and Wesiack, the term remains amazingly pallid and unclear, even though, in my opinion, the contributions converge with coping-research, research about the terms of development of illness among migrants, integrative achievements in relation to social, bodily, and psychological circumstances, etc. Maybe the reference to Schmitz could further assist in the understanding of the concept. Both Uexküll and Wesiack and Schmitz, when referring to the topic of mutual physical adaptation, cite experiments from the 1940s: how two people who are both pulling at separate ends of a saw organize their teamwork (Christian and Haas 1949). Technically, the task is extremely difficult: it is not just a change from 'pull' to 'let go/be pulled,' because the blade would twist if there isn't enough resistance from the more passive collaborator. To add pain to misery, the amount of resistance depends on the structure of the wood, on the strength of the one who pulls, on the quality of the saw, on the angle of the blade relative to the two persons, etc. Given this extremely complicated interaction, I see no likely biomedical model that explains why the task of cutting a trunk down can successfully be accomplished by two lay persons. Do they exchange subliminal 'signs' that elicit interpretants that in turn point to the state of the blade relative to the wood? Instead of seeking an explanation within the realm of particular items, Schmitz explains this instantaneous cooperation without delay with the fact that the cooperative partners become quasi-one through a mutual embodiment in which body refers to the lived body and not the assembly of muscles and sinews (Schmitz 1995: 
137). The basic idea behind this concept of communication between lived bodies includes the concept of a vital drive. Vital drive refers to an innate vitality of living organisms that is not necessarily confined to the region of an individual body; it can encompass a group of individuals singing in a choir or spectators in a stadium who are raised or pulled down by an upflare or a decrease of vital energy in their common felt body shared by all individuals under the glass cover of an atmosphere (Schmitz 2003: 38). The emotional disruption of resonance between a therapist and a depressive patient is understood as a loss of the ability of the patient's vital drive to adapt to an affection of the felt body that indicates the impact of an atmosphere (Schmitz 1995: 128).

Communication as the interaction of lived bodies, leading to successful mutual adaptation could be seen as underlying different phenomena that are familiar to most clinicians:

- the flash phenomenon of a sudden deep understanding in the doctorpatient-relationship as described by Balint et al. (1975: 126)

- the moment when patients and relatives suddenly sense trust and decline any further explanation prior to a surgical procedure

- the physical relief described by Peirce upon a successful sudden abduction: But suddenly when we are poring over our digest of the facts endeavouring to set them into order, it occurs to us that if we were to assume something to be true that we not know to be true, these facts would arrange themselves luminously (EP 2: 531).

\section{Conclusion}

It is hoped that human medicine benefits from a discussion between representatives of different research paradigms and philosophical traditions. Constructivism has the potential to force the physician trained in the application of the bio-medical model to take into account the individual patient and to acknowledge the unpredictability of his or her behavior. Semiotics, especially biosemiotics, offer a terminology that might help to bridge the gap between processes of the body and the mind; from interaction between cells to the interaction between the individual and the environment, life could be seen as the exchange of signs (information). Hermann Schmitz's new phenomenology offers access to a less well defined world without clearly distinguishable particular items.

The object of medicine - the interaction of human beings with human beings - is possibly too complex to be understood by just one model. What von Uexküll wrote in the introduction to his textbook in 1979, in my view is valid for all attempts of defining a theory of medicine: 
A textbook which attempts to describe a developing object should not hesitate to accept its temporary nature and welcome heterogeneous points of view from all parts of the intellectual world. (T. von Uexküll 1979)

\section{Note}

* I give special thanks to Prof. Walter Burger from Berlin who, as a cautious pathfinder, led me through the world of Schmitz and gave me valuable references to one of the first versions of this article and Alex von Sinner from Basel who served as my semiotic chaperone.

\section{References}

Adler, R. H. et al. (eds.). (2003). Uexküll. Psychosomatische Medizin. Modelle ärztlichen Denkens und Handelns. Munich/Jena: Urban and Fischer.

Balint, E. and Novell, J. S. (1975). Fünf Minuten pro Patient. Frankfurt: Suhrkamp Taschenbuch.

Christian, P. and Haas, R. (1949). Wesen und Formen der Bipersonalität. Stuttgart: Enke.

Eco, U. (2000). Kant und das Schnabeltier. Munich: Hanser.

Freud, S. (1912). Ratschläge für den Arzt bei der psychoanalytischen Behandlung. In Gesamtwerke, vol. 8, 376-387.

Hoffmeyer, J. (2003). Molekularbiologie und Genetik in semiotischer Sicht. In Uexküll. Psychosomatische Medizin. Modelle ärztlichen Denkens und Handelns, R. H. Adler (eds.), 97-106. Munich/Jena: Urban and Fischer.

Houser, N. and Kloesel, C. (1992). Introduction to The Essential Peirce: Selected Philosophical Writings, Vol. 1 (1867-1893), xxxvii. Bloomington and Indianapolis: Indiana University Press.

Langewitz, W. (2007). Beyond content analysis and non-verbal behavior: What about atmosphere? A phenomenological approach. Patient Education and Counselling 67 (3), 319-323.

Langewitz, W., Degen, L., and Schächinger, H. (2003). Funktionelle Störungen somatoforme Störungen. In Uexküll. Psychosomatische Medizin - Modelle ärztlichen Denkens und Handelns, R. H. Adler et al. (eds.) 749-795. Munich/Jena: Urban and Fischer.

Langewitz, W. (2008). Der Ertrag der Neuen Phänomenologie für die Psychosomatische Medizin. In Neue Phänomenologie zwischen Praxis und Theorie, 126-140. Freiburg: Karl Alber.

Maturana, H. and Varela, F. (1987). Der Baum der Erkenntnis: Die biologischen Wurzeln des menschlichen Erkennens. Bern: Scherz Verlag.

Peirce, Charles S. (1992). Essential Peirce: Selected Philosophical Writings, vol. 1 (18671893), N. Hauser and C. Kloesel (eds.). Bloomington: Indiana University Press. [Reference to vol. 1 of Essential Peirce will be designated EP 1.]

Peirce, Charles S. (1998). Essential Peirce: Selected Philosophical Writings, vol. 2 (18931913). Peirce Edition Project (eds.). Bloomington: Indiana University Press. [Reference to vol. 2 of Essential Peirce will be designated EP 2.] 
Sack, M. and Lamprecht, F. (1998). Kohärenzgefühl und Salutogenese: Aaron Antonovskys Konzept gesundheitsprotektiver Ressourcen. In Handbuch der Salutogenese, W. Schüffel et al. (eds.) 325-336. Wiesbaden: Ullstein Medical.

Saussure, F. de (1983 [1916]). Course in General Linguistics, Roy Harris (trans.). London: Duckworth.

Schmitz, H. (1995). Der unerschöpfliche Gegenstand - Grundzüge der Philosophie, 2nd ed. Bonn: Bouvier-Verlag.

Schmitz, H. (1997). Höhlengänge. Über die gegenwärtige Aufgabe der Philosophie. Berlin: Akademie-Verlag.

Schmitz, H. (1999). Adolf Hitler in der Geschichte. Bonn: Bouvier Verlag.

Schmitz, H. (2003). Was ist Neue Phänomenologie? Rostock: Ingo Koch Verlag.

Schmitz, H. (2004a). Naturwissenschaft und Phänomenologie. Erwägen Wissen Ethik 15 (2), $147-154$.

Schmitz, H. (2004b). Phänomenologie als Anwalt der unwillkürlichen Lebenserfahrung. Erwägen Wissen Ethik 15 (2), 215-228.

Schmitz, H., Marx, G., and Moldzio, A. (2002). Begriffene Erfahrung. Beiträge zur antireduktionistischen Phänomenologie. Rostock: Ingo Koch Verlag.

Uexküll, J. von (1980). Kompositionslehre der Natur, Vorwort des Herausgebers. Berlin: Propyläen-Verlag Ullstein.

Uexküll, T. von (ed.) (1979). Lehrbuch der Psychosomatischen Medizin. Munich: Urban and Schwarzenberg.

Uexküll, T. von and Wesiack, W. (1998). Theorie der Humanmedizin, 3rd ed. Munich: Urban and Fischer.

Wade, D. T. and Halligan, P. W. (2004). Do biomedical models of illness make for good healthcare systems? British Medical Journal 329 (7479), 1398-1401.

Wolf Langewitz (b. 1951) is Deputy Head at Division of Psychosomatic Medicine/Internal Medicine at the University of Basel. His research interests include communication between health care providers and patients/clients; somatoform disorders; and patient-centered care. 